\title{
Massive Breast Lipoma Operated on by Two Eponymous Giants in 1846
}

\author{
Wilson IB Onuigbo* \\ Department of Pathology, Medical Foundation and Clinic, Nigeria
}

Submission: June 28, 2016; Published: July 18, 2016

*Corresponding author: Wilson IB Onuigbo, Department of Pathology, Medical Foundation and Clinic, 8 Nsukka Lane, Enugu 400001, Nigeria, Email: wilson.onuigbo@gmail.com

\begin{abstract}
The $19^{\text {th }}$ century steadily witnessed the development of Surgical Pathology. Remarkably, a textbook came into use in Britain. It was praised by no other than Sir William Oster in USA. Among the book classifications was lipoma. Therefore, it was gainful to recall a massive case of this tumor that came to light in 1846 following a difficult operation jointly performed by two eponymous giants. Their experience deserves due documentation.
\end{abstract}

Keywords: Breast; Lipoma; Size; Operation; Eponyms; Sir benjamin brodie; Sir astley cooper; History

\section{Introduction}

Elsewhere, [1] I reviewed the historical progress made in surgical pathology during the 19th Century. Incidentally, this period witnessed the birth of Beales'e personal textbook called The Microscope in Medicine. [2] Indeed, so widely appreciated was it that the USA-based Sir William Osler [3] praised him very highly in an obituary. With reference to our present concern, one of his classifications was lipoma. Interesting insight is, therefore, provided here with reference to avid appreciation of historical highlights.

\section{Historical Text}

An eponymous giant, Sir Benjamin Brodie [4] in 1846 published "Lectures illustrative of pathology, and surgery." Indeed, it contained the highly illustrative story of the gratifying management of a patient as follows: A lady had an enormous tumor of the breast. It did not feel very different from the natural breast, but it seemed like a breast of a monstrous size. Sir Astley Cooper saw the patient with me. There is such a disease as hypertrophy of the breast; that is a morbid increase of the gland, without any actual alteration of structure; and both Sir Astley and myself was inclined to believe that such was the nature of the disease in this instance. The tumor continued to grow; the patient became tired of carrying it about, and we recommended her to have it removed. Sir Astley Cooper was present at the operation, and we set about it, believing that I should remove the whole breast. When, however, I had made the first incision, I found that the breast lay perfectly sound in front, expanded over the surface of a large tumor which was situated between it and the pectoral muscle. The first portion of the tumor which I exposed had the appearance of the chronic mammary tumor; then I came to a mass of fat; then to the other structure again. In short there was a fatty tumor and a chronic mammary tumor blended with each other. The entire mass probably weighed between two and three pounds. The patient recovered; and up to this time, that is, at the end of seven years, there has been no recurrence of the disease.

\section{Discussion}

It is accepted not only that there are medical truths in historical perspective [5] but also that the literature of the life sciences has historical background. [6] Also, I am persuaded that the visionary views of the medical masters of yester years are worthy of recall. [7] Hopefully, in the present paper, the challenges firmly faced by two eponymous giants have come to light pleasantly. Yes! May such firm fruitful footsteps be followed by present practitioners.

\section{References}

1. Onuigbo WIB (2015) The surgical pathology of cancer: A historical review. J Cancer Prev Curr Res, 2(3).

2. Beale LS (1852) The microscopy in medicine. London, UK, Highley.

3. Osler W (1906) Obituary notice on Beale. Lancet 1: 1004.

4. Brodie BC (1846) Lectures illustrative of various subjects in pathology and surgery. London: Longman, Brown, Green and Longmans. 
5. Moser KM (1987) Medical truths in historical perspective. Heart \& Lung 16(4): 345-346.

6. Kronick DA (1984) Literature of the life sciences: The historical background. Bull N Y Acad Med 60(9): 857-875.
7. Onuigbo WIB (2015) The visionary views of medical masters of yester years on Nature's norms point to present prospects in the target therapy of cancer. Biol Med 7: 221. 